\title{
The Universe Observing Center a modern center to teach and communicate astronomy
}

\author{
Salvador J. Ribas \\ Parc Astronòmic Montsec, Consorci del Montsec \\ Camí de Coll d'Ares s/n, 25691 Àger, Lleida, Catalunya, Spain \\ email: sjribas@montsec.cat
}

\begin{abstract}
The Universe Observing Center is one of the parts of the Parc Astronòmic Montsec (PAM). PAM is an initiative of the Catalan government, through the Consorci del Montsec (Montsec Consortium), to take advantage of the capabilities and potential of the Montsec region to develop scientific research, training and outreach activities, particularly in the field of Astronomy. The choice of the Montsec mountains to install the PAM was motivated by the magnificent conditions for observing the sky at night; the sky above Montsec is the best (natural sky free of light pollution) in Catalonia for astronomical observations. The PAM has two main parts: the Observatori Astronòmic del Montsec (OAdM) and the Universe Observing Center (COU). The OAdM is a professional observatory with an $80-\mathrm{cm}$ catadioptric telescope (Joan Oró Telescope). This telescope is a robotic telescope that can be controlled from anywhere in the world via the Internet. The COU is a large multipurpose center which is intended to become an educational benchmark for teaching and communicate astronomy and other sciences in Catalonia. The management of the COU has three main goals: 1) Teach primary and secondary school students in our Educational Training Camp. 2) Teach university students housing the practical astronomy lectures of the universities. 3) Communicate astronomy to the general public. The COU comprises special areas for these purposes: the Telescopes Park with more than 20 telescopes, a coelostat for solar observations and two dome containing full-automated telescopes. The most special equipment is "The Eye of Montsec", with its $12 \mathrm{~m}$ dome containing a multimedia digital planetarium and a platform for direct observation of the sky and the environment. During 2009 we expect around 10000 visitors in Montsec area to enjoy science with Montsec dark skies and an special natural environment.
\end{abstract}

Keywords. astronomy,planetarium,museum

\section{Consorci del Montsec}

The Consorci del Montsec is a public institution created by the Catalan government to implement a regional development project in this area of Catalonia which, by taking advantage of its capabilities and potential, helps to redirect and improve its socioeconomic situation. The major aim of the Consorci is to comprehensively develop the tourist, social and economic sectors of Montsec. Among other organisations, this initiative has involved 16 municipalities, two County Councils, Lleida Regional Council and several departments of the Catalan government.

The main activities of this consortium are related to the natural enviroment, being the astronomy outreach activities the most important part. The most recent activies are:

- Parc Astronòmic Montsec (PAM)

- Birding routes in this area

- Trekking routes 
- Gastronomical initiatives (e.g. honey promotion)

\section{Parc Astronòmic Montsec}

The Parc Astronòmic Montsec (PAM) is an astronomical equipment of Consorci del Montsec. The major objectives of PAM is to offer updated infrastructures focused to research and communicate astronomy (main topic) and natural environment (geology, fauna and flora). These infrastructures and materials will allow to accomplish educational objectives in several levels (from primary education to university students) and outreach activities to the general public. Finally, PAM will increase scientific touristic activities that will allow to maintain regular affluence of public to this area.

PAM is located in Montsec mountain range (see Fig. 1) in the North-East of Iberian Peninsula, around $180 \mathrm{~km}$ from Barcelona. Montsec is a calcareous mountain range more than 40 kilometers long, covering an area of 18,696 hectares divided between Aragon and Catalonia. PAM has two main parts: the observatory and the Universe Observing Center. The observatory is placed on the top of the mountain and the Universe Observing Center is placed in the Ager Valley in Montsec area.

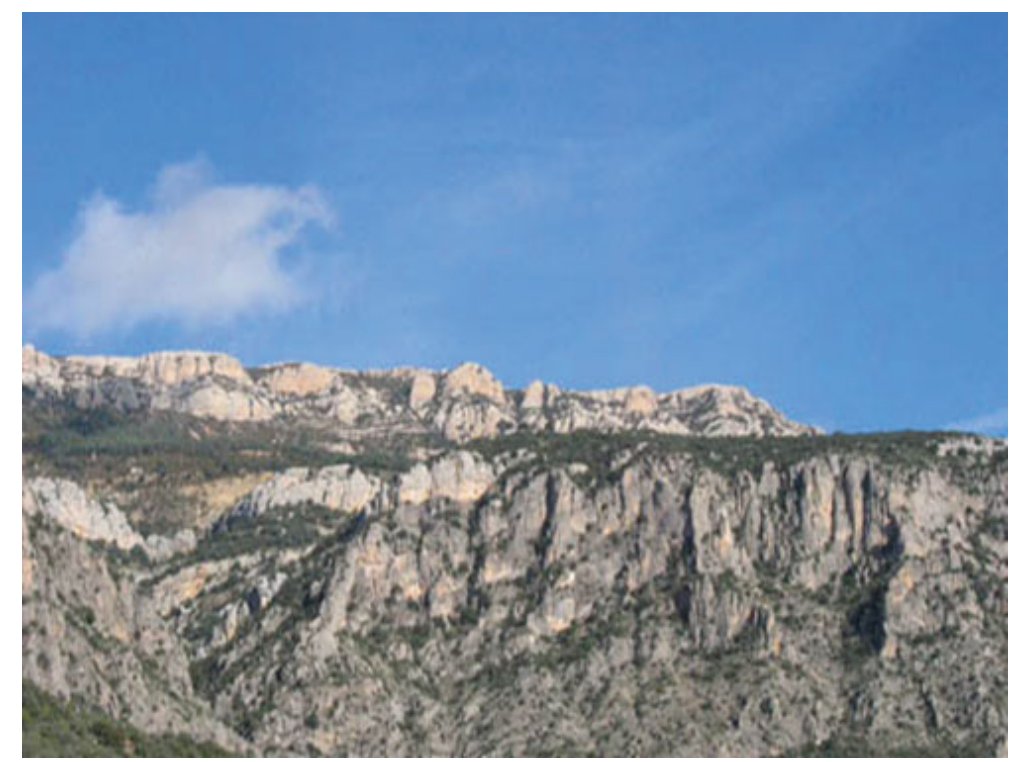

Figure 1. View of Montsec mountain range.

This project was installed at Montsec region because this is the best place in Catalonia for astronomy due to:

- Special meteorological conditions

- A sky free of light pollution

- An exceptional natural environment

The site-tests showed that Montsec mountains have one of the lowest humidity levels of Catalonia and moderate rain indexes. Some imaging tests show that Montsec has high atmospheric stability due to a particular wind regime. So, a high number of nights with clear skies (more than 60\%) are available in Montsec area. In addition, this is the darkest sky of the whole Catalonia. Ground-based studies show that Montsec skies are 80 times 
darker than the Barcelona sky and Montsec skies are considered free of light pollution (natural sky) and are specially protected by the Catalonian Light Pollution law.

\section{Observatori Astronòmic del Montsec (OAdM): A brief summary}

The Observatori Astronòmic del Montsec (OAdM) is located on the top of the mountain (see Fig. 2), at 1570 meters above sea-level. It is placed in a small town called Sant Esteve de la Sarga (Pallars Jussa). This is the research part of the PAM project and basically this observatory is devoted to general astronomy research and Ph.D. practical lectures. The OAdM contains an $80 \mathrm{~cm}$ telescope, called Joan Oro Telescope honoring this catalan scientist.

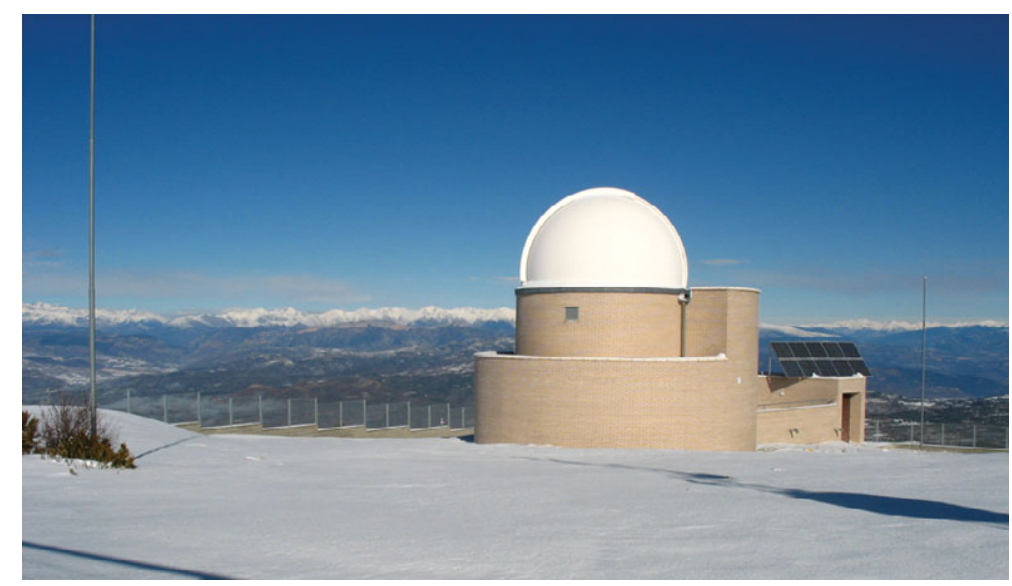

Figure 2. View of the Observatori Astronòmic del Montsec in winter.

The Joan Oró Telescope will be a fully robotic telescope. Actually, the Catalonian Space Studies Institute is doing the installation of the robotic systems. This observatory will control many enviroment variables to prevent any kind of problems in the telescope during robotical observations (humidity levels, rain, clouds, storms). Since October 2007, our observatory is obtaining the first scientific results during the calibrations tests, for example the follow-up of $17 \mathrm{P} /$ Holmes outburst, studies of transiting exoplanets or variable stars.

\section{Centre d'Observació de l'Univers (COU)}

This Universe Observing Center (COU) is the educational and outreach part of Parc Astronòmic Montsec. It is placed in Ager (La Noguera) at 800 meter above sea-level and $15 \mathrm{~km}$ far from the OAdM. COU uses the natural environment to explain to the visitors geology, fauna and flora. The clear skies without light pollution allow the visitors to do a lot of astronomical activities. This is a center opened to a large kind of people: primary and secondary students, university students and general public. The center was inaugurated the 16th of January of 2009 and are starting all the activities during the firsts months of this International Astronomy Year.

The COU is divided in three main areas:

- Central Building

- The Telescopes Park 
- The Eye of Montsec

\subsection{Central Building}

The Central Building contains the reception and offices of the Center, the standard classroms, the computer classrooms and the Permanent Exhibition of this Center. This Central Building houses a permanent exhibition covering the main areas of interest of the COU: astronomy, obviously, but also the geology, fauna and flora of the Montsec region are given pride of place. The exhibition reproduces and analyses the different habitats in the Montsec region and gives an overview of its geological history, including all the huge transformations the Earth has gone through since it was formed. The astronomical section gives an overview of the main topics in Astronomy, from the Big Bang, the formation of galaxies and the evolution of stars and black holes through to the detection of other planets and our neighbours in the Solar System (see bottom image of Figure 3).

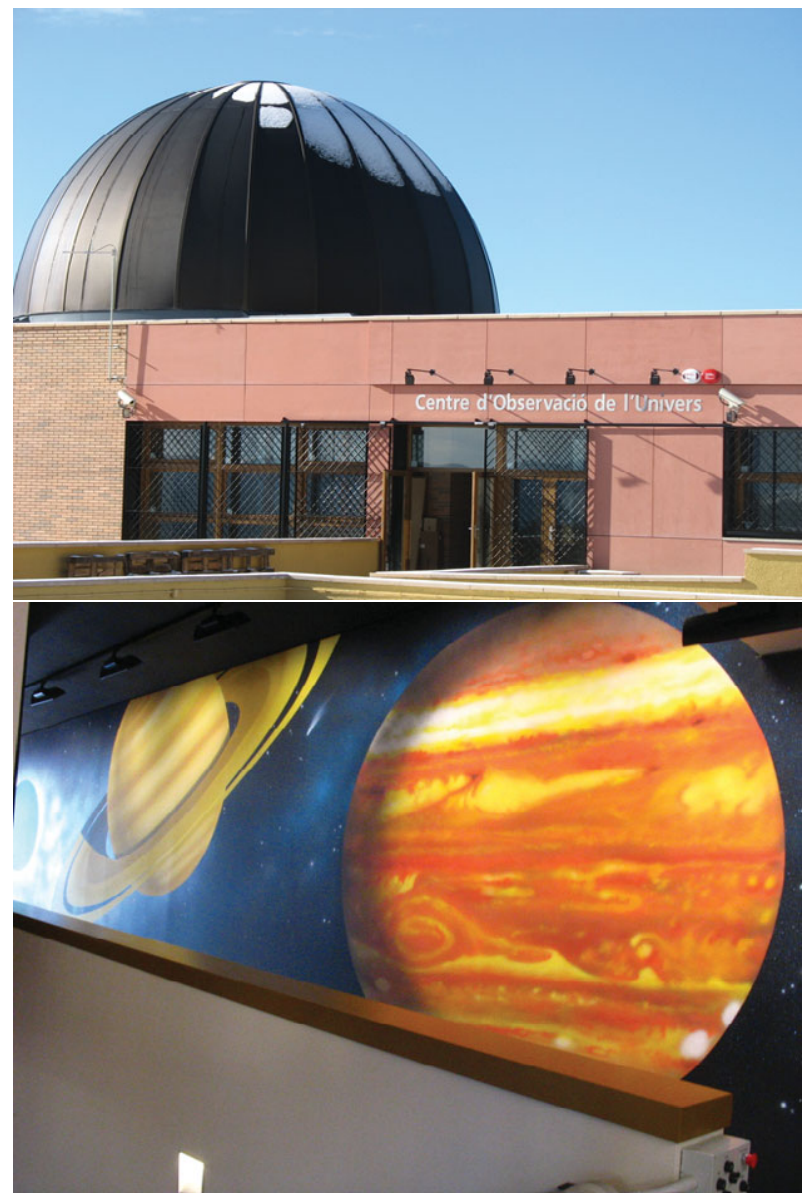

Figure 3. Top: General view of Centre d'Observacio de l'Univers. Bottom: The Solar System in the permanent exhibition. 


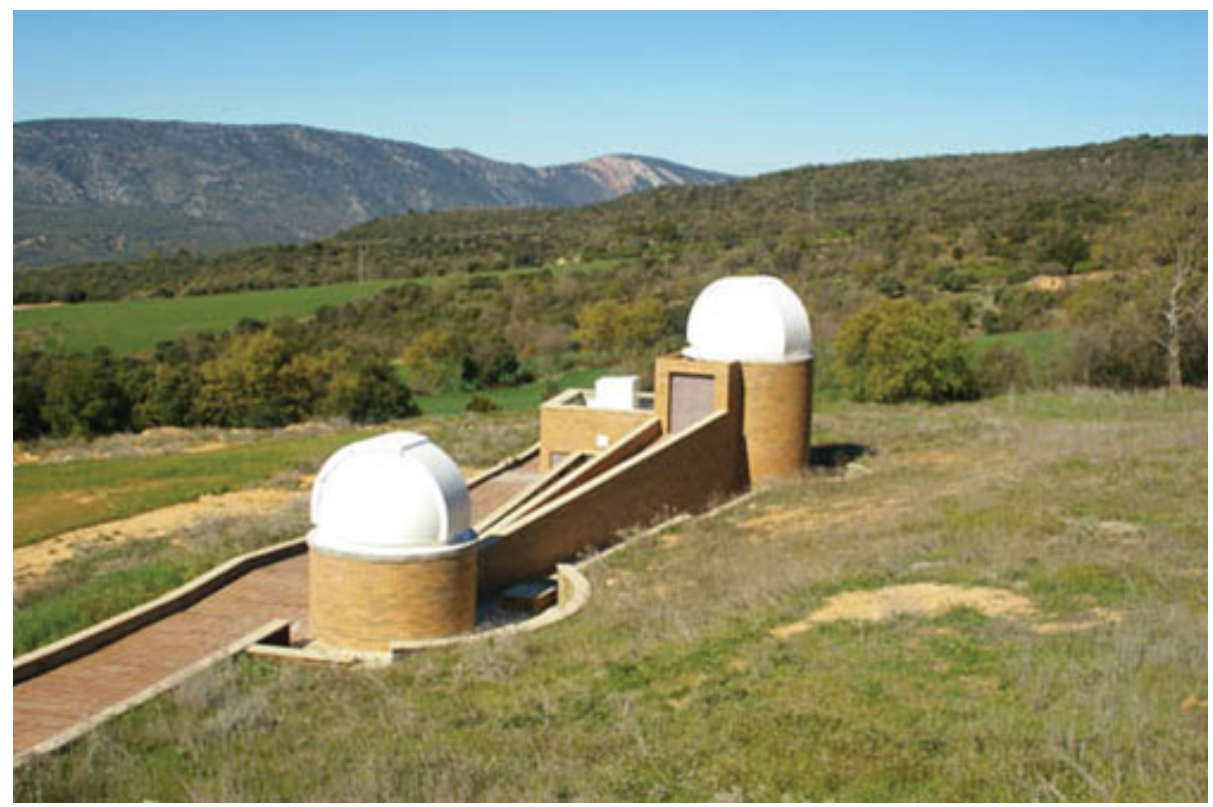

Figure 4. View of the two domes of the Telescopes Park.

The Telescopes Park is the outdoor section of the Universe Observing Center. This area is devoted to observing the sky during day and night. It consists of two buildings with astronomical domes (see Figure 4) and an area for setting up the COU's portable telescopes. The equipment of the Park consists of:

- A Schmidt-Cassegrain 16 inches telescope in the big dome.

- A Takahashi $15 \mathrm{~cm}$ refractor telescope in the small dome.

- A coelostat that projects the image of the Sun to a small classroom (25 persons of capacity).

- More than 20 portable telescopes.

\subsection{The Eye of Montsec}

The Eye of Montsec is an exceptional multimedia facility consisting of a multimedia digital planetarium which recreates the current sky as well as those of any other period and also shows films in the full dome screen format, allowing visitors to appreciate other aspects than purely astronomical ones, projected onto a 12-metre diameter dome.

With capacity for around 70 people, the Eye of Montsec is equipped with highly advanced audiovisual equipment comprising seven audiovisual projectors (Barco) and a sound system controlled by computer systems. The planetarium system is DigitalSky 2 of Sky-Skan co.

Thanks to its retractable dome (see Figure 5) and front wall, the Montsec Eye gives viewers an uninterrupted view of the sky above Montsec which is almost totally free of light pollution. This direct observation is accompanied by the images obtained by a 30-centimetre diameter telescope installed in the same room, which displays the images on small TFT screens in the seating area. 


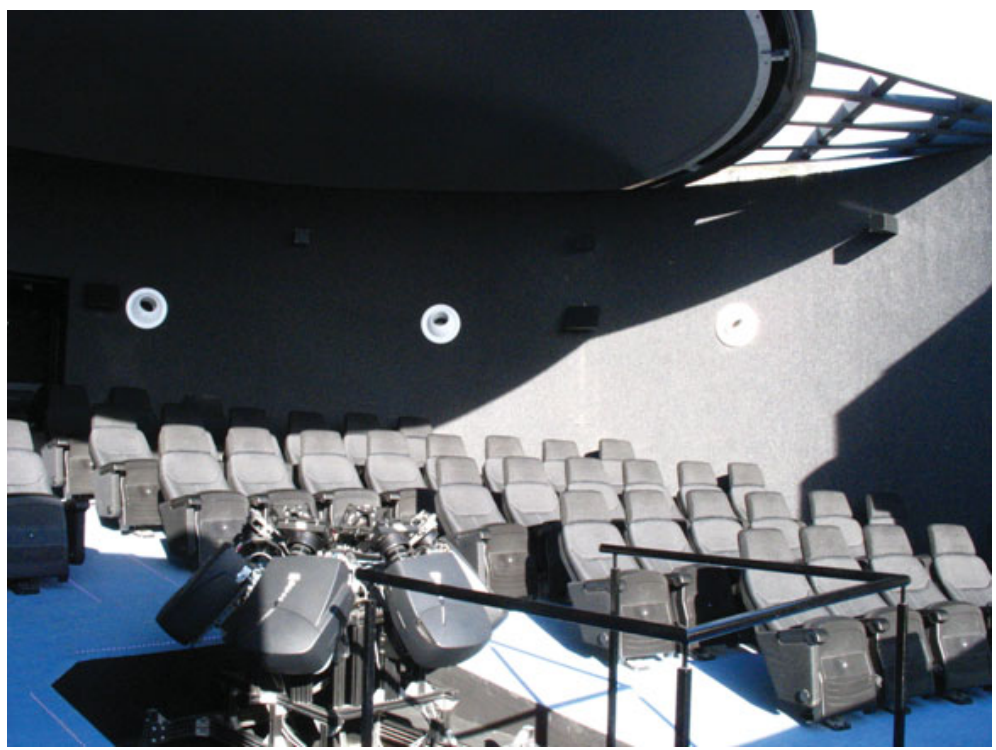

Figure 5. View of the Eye of Montsec with its retractable dome partially opened.

\section{Our visitors}

We are having visitors from:

- Primary and Secondary school students: These students will go to COU through Camp d'Aprenentatge del Montsec (Montsec Education Camp) of Education Department of Catalonia. This Camp opened the past 11th of February and more than 3000 students per year will visit the center.

- Astronomy University students: The astronomy students of University of Barcelona will do their practical lectures in our center. These lectures will start during second half of 2009 .

- Amateur astronomers and general public: During weekends and holidays we will do visits, observations, planetarium sessions and courses to general public. These visits started in April 2009 and during the firts month we had more than 3000 visitors.

\section{References}

http ://www.parcastronomic. cat

http: //www. montsec.cat 